\title{
The Impact of Smart Glasses on a New Generation of Users
}

\author{
Qi Yutong, UCSI University, Malaysia \\ Ju Hang, UCSI University, Malaysia \\ (iD) https://orcid.org/0000-0003-0259-1855 \\ Jing Rui Chen, UCSI University, Malaysia \\ P. S. Joseph Ng, UCSI University, Malaysia
}

\begin{abstract}
Intelligent glasses are similar to the smart phone, which possesses an independent operational system, and it can use diverse functions and applications by installing software. Intelligent glasses also are regarded as one of the more popular intelligent pieces of equipment in the resent years. Intelligent glasses are in an early stage of development, so there are some core hardware and application fields that are still researching and exploring continually; but its development will be quite rapid and the scale of the market will also expand continually in the near future. Intelligent glasses have a high requirement for the quality of data transmission. With the advent of $5 \mathrm{G}$, the experience and significance of intelligent glasses will increase sharply.
\end{abstract}

\section{KEYWORDS}

Art, Business, Education, Electricity, Image Recognition Technology and Augmented Reality Technology, Intelligent Glasses, Social, Speech Recognition Technology, Transportation, Travel

\section{INTRODUCTION}

Market scale of global smart wearable equipment and the market scale of Chinese intelligent glasses. The market scale of global smart wearable equipment industries just have 230 million yuan in 2011, And then the marker scale of global smart wearable equipment rapidly increased and had broken 10 billion yuan in 2015, By the 2017, It had increased to 264.2 billion yuan(Suh \& Roh,2015). In 2018, The global scale was around 339 billion yuan. By now, it have attained to 433 billion yuan and evaluate the market scale which will break one hundred billion yuan. Thereinto, The market scale of intelligent glasses is 100 million yuan in smart wearable equipment, In 2019, its market scale had attained to 2.2 billion yuan, By far the scale have been close to 50 billion yuan. Estimating the market scale of Chinese intelligent glasses will increase to around 83 billion yuan in 2023 (Brohma and Glanz-ChanosGrunert, 2017). Its average increment rate is $39.37 \%$. Although the proportion of market share of Chinese intelligent glasses is fewer than global market. But The market share will enhance continually. The clients of intelligent glasses are ordinary customers and enterprise customers. The intelligent glasses is a update product as smart phones to be researched and produce. Meanwhile the intelligent glasses possess a lot of functions which can enhance the work efficiency of users in terms of enterprise customers (Gong et al. 2021). Instead of The Porsche company use 
the projection technology of intelligent glasses to show the various parts of car chassis, which the light is inadequate, In this way it increase testing efficiency. So the intelligent glasses possess more wider marker place in the future.

\subsection{Analyzing the Environment}

Analyzing the development prospect of intelligent glasses industries. About the integrative functions of intelligent glasses. The intelligent glasses possess independent operation system, which the users can realize a lot of functions which includes communication of voice and video, informational transmission and pictures identification by the action and voice to control it. The functions of intelligent glasses have several primaries function in the following.

The functions of reminding information and notices. The intelligent glasses can show some relevant information on eyeglass directly. Users will experience this amazing visual effects. Meanwhile, They also can conduct detailed read and further check what they want to know by voice and manual control.

The function of voice transmission. Users can realize voice input by the built-in microphone to record it, And then it will send voice information to other electronic equipment.

The function of map navigation. Users can gain location information by the intelligent glasses inside map, And according to the users current location timely update surrounding road condition and transportation data on the internet.

The functions of photograph and video. Users can use the camera of intelligent glasses to take pictures and record video, Meanwhile, The voice control can liberate people hands, Moreover, people can realize eyes control technology, Such as blink of an eye picture.

Intelligent glasses have a projection function. So you can watch your favorite movies and TV shows alone. The Bluetooth headset can be connected to the glasses at any time. And it has a phone call function so that people's hands can be released.

The video calling functions of intelligent glasses. Users can conduct video calling with friends in any internet position by inside camera of intelligent glasses. In this case people can see each other and two sides can conduct interaction. The AR intelligent glasses will replace smartphone in the future, Because, Nowadays a majority of AR intelligent glasses had provided total of functions which smartphone possess, even some was more exclusive than smartphone, and the independently of AR intelligent glasses had been more strong. Moreover, It can also be compatible with third application programs effectively. In this case it will bring more worthy applications for customers. Like shipping, watching 3D films, adjusting vision, playing virtual games, remote education and so on(Hafsa and Majid,2020). These application scene of function is that smartphone cannot do. Because, it is feeling of auditory sense and visual sense, it will replace smartphone in the near future.

\subsection{Analyzing the Strategic Direction of Intelligent Glasses Industries}

AR intelligent glasses have wide application in different fields

Industries field: The intelligent possess wide application potential in industries field, For example, It can liberate people hands and realize real-time interaction. Especially, In the process of transportation test, The intelligent possess decline the expenses of human resource cost and protect the workers safety, enhancing efficiency (Atallah 2021, Tan Y.Y. 2020). Meanwhile, The intelligent possess also can identify equipment in the test process. In this way it will avoid incorrect in operating (Han Tom Dieck and Jung 2019). Moreover, intelligent possess will synchronously record test and operational data by its video and camera functions to show to the workers as a reference.

Medical field: The intelligent possess that combine with AR will structure a 3D body model of patient. Which can appearance the profile of skin, heart and so on. Meanwhile, AR intelligent possess can conduct precise and efficient to synchronize patient's medical record information and record relevant data for early finding sickness(Matsuhashi and Kurokawa2020). It will maximally ensure people's life safety to effectively subtract death rate (Vica 2019, 2020). Therefore, The AR 


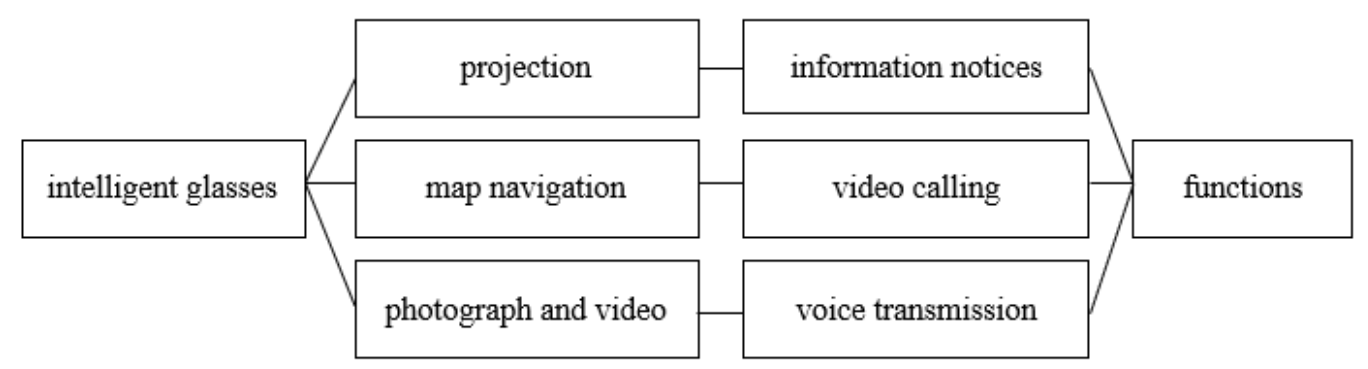

intelligent possess can also live broadcast by the first perspective of doctor and restore this entire process of surgery at any time. In this wat can also enhance quantity of surgery.

\subsection{Research Objective}

1. To identify to what extent evaluation of outcomes and beliefs affect consumers attitudes and intention to purchase in the smart glasses market .

2. To develop a framework on the effects of external influence and internal influence which affect self-concept and life style of the consumer which result in purchasing decision making process.

3. To analyse what are the factors which influence and eventually motivate the customer to buy smart glasses in market.

4. To analyse the theoretical implication of brand of smart glasses in market and what are the effect on purchase decision making process.

Figure 2. Virtual reality technology in smart glasses

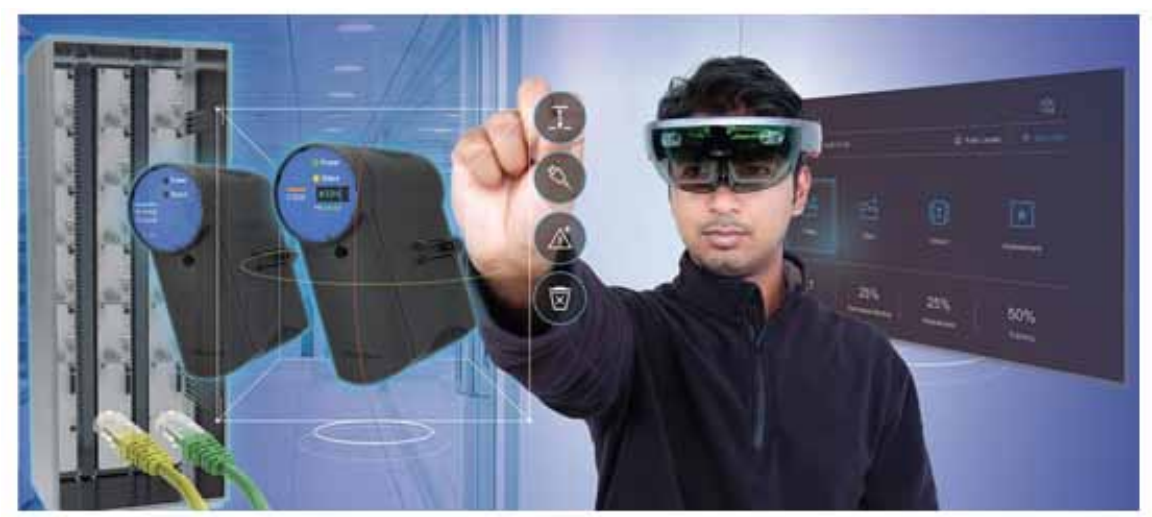




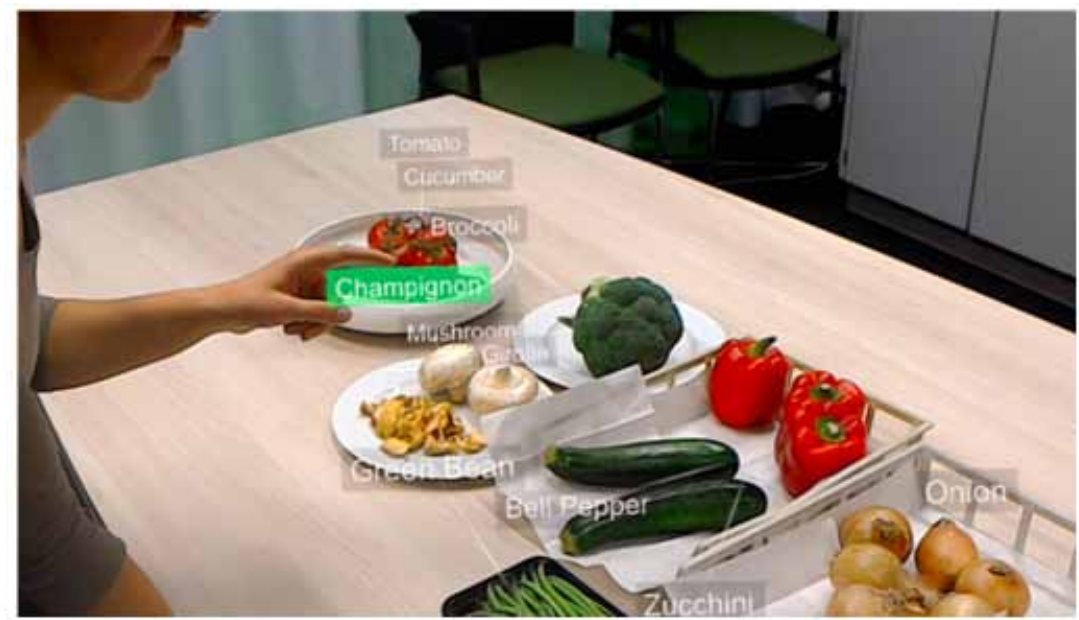

\subsection{Research Questions}

1. How do attitude and subjective norms affect consumer behaviour towards smart glasses in the Market?

2. What are the effect of culture, social status and marketing activities in form of external influence on the consumer for purchasing smart glasses in the market?

3. What are the effect of perception, motivation and emotion in form of internal influence on the consumer for purchasing smart glasses in the market?

4. How does social concept and lifestyle affect the consumer decision making process in the market?

5. Does the consumer if affected by the cost and features of smart glasses while purchasing? Does it affect consumer social status?

\subsection{The Smart Glasses Research Hypotheses}

Hypothesis 1. The determination of the results and the evaluation of beliefs influence consumers' attitudes towards purchasing smart glasses.

Hypothesis 2. The framework of external and internal influences on consumers' lifestyles and leads to purchasing decisions

Hypothesis 3. Product features have an impact on consumers buying smart glasses.

Hypothesis 4. Marketing activities have an impact on consumers buying smart glasses.

\section{LITERATURE REVIEW}

In recent years, mobile technology and wearable technology have developed rapidly. In particular, smart glasses are one of many emerging wearable computing technologies today. Therefore, it is of great significance to study the safety, privacy, design and influence of the new smart glasses. Smart glasses create new augmented reality experiences that enhance user perception and interaction, thus creating new research opportunities and challenges for security and privacy. These challenges may stem from the fact that smart glasses have countless sensors that can be turned on all the time. These are cameras, microphones, GPS, accelerometers, gyroscopes and compasses. Multiple output devices (head-up display (HUD), speakers). In addition to being able to execute multiple applications in 


\begin{tabular}{|l|l|}
\hline $\begin{array}{l}\text { Strengths: The AR smart glasses can make people see } \\
\text { virtual reality images, This is a reformation of auditory } \\
\text { sense and visual sense for human rise. }\end{array}$ & $\begin{array}{l}\text { Opportunities: The AR smart glasses will be same as the } \\
\text { smart phone, which possess exclusive operation system. } \\
\text { And users can install various software and services which } \\
\text { contain video software, game software ang so on. }\end{array}$ \\
\hline $\begin{array}{l}\text { Weaknesses: The smart glasses developers may not } \\
\text { consider their technology's privacy concerns. }\end{array}$ & $\begin{array}{l}\text { Threats: Social risks to social cohesion, the extent to } \\
\text { which consumers expectations of smart glasses reduce the } \\
\text { amount of social behavior in society as a whole. }\end{array}$ \\
\hline
\end{tabular}

the background and communicate wirelessly with other devices, as well as connect to the Internet. Furthermore, these wearable devices can be considered as part of the Internet of Things (IoT).

\subsection{Strengths of AR Smart Glasses}

AR will entirely enhance the experience of customers. The AR smart glasses can make people see virtual reality images, This is a reformation of auditory sense and visual sense for human rise. Meanwhile, The AR smart glasses can collect customers demand rapidly along with sending relevant information to them. This interactive method can structure a full range of effect. Other than that, The 5G technology will promote the AR smart glasses to rapid development.

Firstly, By now, The AR smart glasses have realized video transmission, 3D video or graphics processing, multi-perspective Integration of audio and video effects and so on, These functions need to expend amount of data traffic, The $4 \mathrm{G}$ internet rate is not adequate. It need to depend on $5 \mathrm{G}$ technology to solve. Secondly, AR smart glasses provide high distinct video in mobile environment, But It is restricted to processing ability of equipment, saving place and battery capacity, If would like to overcome the problem, It need to introduce cloud processing and 5G internet can solve problem of High bandwidth and low latency.

\subsection{Internal Weakness in the Smart Glasses Market}

Although it is well known that smart glasses developers may not consider their technology's privacy concerns, as they are mainstream for applications such as ads and search results that are customized for them. Collect digital trails and behaviors of consumers. We know that responsibility and trust are one of the cornerstones of cyber and information security. In addition, security threats can be easily associated with the operating system. Since Android is a popular operating system for smart glasses, the same threats to Android security apply to smartphones. Some vulnerabilities allow attacks that make devices partially or completely unavailable, or enable AR attackers to monitor or steal users' data. Other threats include existing Android malware, or viruses, that can infect devices through malicious applications.

\subsection{External Threat in the Smart Glasses Market}

Social norms or normative beliefs indicate social influence and represent a person's personal beliefs about whether his/her closest people want or disapprove of a certain behavior. Smart glasses can have a negative social impact because they interfere with people's normal ways of communicating in an undesirable way. For example, smart glasses could record users without their knowledge, which is a violation of their individual rights, or users might focus their attention on online content during a conversation. Under normal circumstances, both of these examples would be considered socially unacceptable behavior. In fact, the term "eyeglasses" has been coined for smart glasses users who voluntarily or unwillingly violate these social norms of behavior. The social norms that exist in society against the use of smart glasses could cause problems for their large-scale adoption.

Social risks to social cohesion, the extent to which consumers' expectations of smart glasses reduce the amount of social behavior in society as a whole. This concern is due to consumers wanting 
smart glasses users to use information in an asymmetric opportunistic way, thus undermining social norms for non-opportunistic behavior. For example, smart glasses users might be able to look up personal information in conversations and use that information to their advantage. Social cohesion could pose a threat to the market for smart glasses.

\subsection{Opportunity of AR Smart Glasses}

The AR smart glasses will be same as the smart phone, which possess exclusive operation system. And users can install various software and services which contain video software, game software ang so on. In comparison with smart phone, It can also operate a majority of functions, which include map navigation, taking pictures, recording video and interacting with friends by action and voice to control. Moreover, The AR smart glasses is one of equipment that can be wore. And It is small volume, portable and convenient, I think that the AR smart glasses will change people lifestyle, Therefore, It is regarded as an important increment point in the near future.

\subsection{The Contribution of Cost Impact to Value}

Perceived cost value determines the behavioral willingness to use the purchased technology. Again, this factor is well established, smart glasses come in a wide range of costs. We believe that the prices, which are widely used in manufacturing and used by almost all shop operators, must be modest so that companies can afford them. Obviously, the price limit depends on the company's purchasing budget, but we estimate that the maximum cost is generally around $\$ 1,000$. Prices much higher than that often act as a barrier to investment, especially for a pair of consumer wearables, which are not expected to last more than a few years. What is certain, however, is that the price of smart glasses will fall dramatically in the coming years as they begin to become widely adopted, leading to mass production of consumer products (similar to the development of mobile phones).

\subsection{The Contribution of Efficiency to Value}

Smart glasses and augmented reality devices have the potential to enhance or even replace existing technology solutions in corporate supply chains and, in some cases, even change the structure of work environments. Pilots with head-mounted displays have demonstrated use cases for improving productivity, productivity, and compliance, which will only grow as the technology matures. Initial implementations will be driven by logistics, maintenance, and assembly functions, but as the device gains more mainstream use, companies will be more willing to experiment with the technology in different environments.

When used effectively in the right Settings, smart glasses and AR displays offer a number of important advantages over computers, tablets, and other prior art technologies: contextual information, increased workflow standardization, hands-free help, and documentation.

Smart glasses can provide data and virtual commands to employees as they complete their work, allowing them to work in a way that doesn't require manual manipulation. Virtual directives are being used to standardize workflows in industries where the labor force changes seasonally, such as e-commerce logistics, and in complex, fast-changing tasks, such as maintenance and repair. With audio and video capabilities, employees can interact with other colleagues and seek help from experts in their organizations, anywhere in the world, on complex issues. Such productivity increases the cost-effectiveness of supply chain operations, speeds up problem resolution, and reduces the number of quality errors. When performing complex tasks, employees can summon interactive on-demand training videos that overlay augmented reality in their environment.

\subsection{The Contribution of Branding of the Organization to Value}

Consumer researchers have long known that products or brands used in public places have social connections. It's also a famous discovery from fashion marketing, the way people dress themselves and present themselves in a certain way. Like other wearable devices, smart glasses are a new fashion 
accessory. So, while there is little research in this area, it is likely that psychological similarities between fashion adoption and smart glasses do exist. Some researchers believe that people whose use and wear of smart glasses are common among their peers are more likely to adopt them.

In addition, previous research has shown that users of (new) technologies often form communities, and within communities, connections between members are an important determinant. In fact. Several smart glasses communities have been set up. For example, EduGlasses.com is a resource center and online community for educators who use smart glasses in classrooms and other educational Settings. GoogleGlassForum.net is another online community dedicated to the Google smart glasses project. These examples will allow registered users to participate in all kinds of discussions related to smart glasses. Research on online communities reveals the importance of social factors that drive user engagement.

\subsection{Product Orientation}

Google Glass is well-known by everyone, but it has not been successful. On the one hand, technology has not perfected the product with good performance. On the other hand, the market response has not received the attention of light perception. Therefore, in terms of product positioning, choosing to follow quickly will avoid investing too much research and development costs. You can upgrade the existing technology system and add the latest technology to integrate the transparent glass display technology with the human eye. And to promote products for specific industries, such as in the taxi field combined with modern calling software to locate passengers in real time, and display the passenger's destination route on smart glasses, saving the driver a lot of time to find passengers.

As a travel assistant's choice, to arrive in a strange city, you need to go to different scenic spots. People no longer need to explain any knowledge about them. Smart glasses capture the history of scenic spots based on positioning and video, and explain the tourist crowd in real time. For the privacy and ease of use of the product, video enthusiasts always release the freedom brought by double talk, which is accepted by more users, breaks away from the shackles of mobile phones, and achieves that smart glasses can solve all the functions of mobile phones.

Therefore, the product is targeted at guides who frequently use maps, as well as drivers and travel enthusiasts. Those who are keen on technology products make decisions based on product function customization.

\section{METHODOLOGY}

This chapter describes the method of completion of the research, summarizes the overall research philosophy adopted by the research, demonstrates the selected methods, and defines the operational structure and the specification of indicators. The determination of the research objectives is based on the previous research of the relevant literature in Chapter 2. The methods used in this study are mainly based on empirical and questionnaire survey methods (JosephNg 2015-2021). Therefore, it is important to evaluate the research methods and scope used by relevant researchers. And how to consider these methods and justify the selected methods.

Collect data and analyze it through questionnaire surveys. An investigation of ordinary adults on personal use intentions and adoption of smart glasses in the future development of smart glasses.

\subsection{Research Design}

This research uses quantitative research. Quantitative research is mainly about statistical analysis of data collected through surveys through questionnaire surveys or other methods. The method of quantitative research is adopted in this research because the findings of the research are accurate, and the purpose of the research is to test the hypotheses stated in the research. In addition, quantitative research can extend the results obtained through representative sampling to other environments. These characteristics of quantitative research make it suitable for this research. 


\begin{tabular}{|l|l|}
\hline Dimension & $\bullet$ Random Variable \\
\hline Methodology & Mixed Mode \\
\hline Data Colletion & Personal, Mass Survey \\
\hline
\end{tabular}

\subsection{Population and Sample}

The target population of this study is adults. Adults are the largest population group. And adults and young people have high purchasing power. They have modern thinking and want to experience new applications, so adults 18 years of age or older are suitable target groups for this study.

\subsection{Sampling Technique}

Due to the large population of China, it is difficult to obtain a prepared population sampling frame. Therefore, this study adopted an online sampling method and randomly adapted 112 people as the sample. Pass 112 valid questionnaires randomly selected. The study used this non-profit sampling technique because the units selected in the sample are time-saving and easy to access, which allows researchers to obtain sample sizes relatively quickly and cheaply.

\section{QUESTIONNAIRE ANALYSIS}

\subsection{Analysis Method}

The statistical chart vividly shows the results of the survey. Each questionnaire is reviewed to ensure the authenticity and reliability of the survey results and to minimize the error caused by human factors. Therefore, using the statistical graph of the data, combined with the common sense of the Internet, to analyze the survey results.

Before data processing, the value of variables in the data, the logical relationship between variables, quotas, etc., were checked, the unqualified samples were checked, deleted and supplemented, and part of the variables were coded after the fact.

\subsection{Mix Mode Methodology}

Smart glasses display virtual 3D of real objects to the user's physical environment, or through smart glasses for various interactions, watching streaming media, and industrial assembly applications, or navigation. We believe that smart glasses that integrate multiple technologies will bring people more fun and convenience in life. We assume that smart glasses can change people's lifestyles and are a positive factor in perceived usefulness and perceived enjoyment. Therefore, we indirectly used mix model methodology. We also collected 112 questionnaires on the acceptance of smart glasses and applied the spss method. After quantitative analysis and qualitative judgment, our research model has been confirmed, which shows that the functions of smart glasses and technological development will bring about people's acceptance of technological products.

We will sample to 30 people and interate into 2 groups for judging the relationship between function and purchase. Intention, And than We will calulate their propabiolity, covariance and correlation by comparing value to plan our produce design scheme. We define some hypothesis and research object, which include high-end function product and low-end function Product, If customer buy our high-end product, we will get 800 otherwise 500. One group, We had collected a important data by sampling to 30 people, There are 25 people, who tends to buy high-end function product and pay 800 yuan, among 30 people, Other one group, There are 15 people, who tends to buy low-end function product and pay 500 yuan.

We can calucate the joint probability by data as follow, We are based on different function product design to gain the purchase trust probability of customer, which is $41.5 \%$. 


\begin{tabular}{|c|c|c|}
\hline & High-end Function Product (A) & Low-end Function Product (B) \\
\hline Value & 800 & 500 \\
\hline Not Purchase & 0 & 0 \\
\hline Number & 25 & 15 \\
\hline Probability(A/B) & $83 \%$ & $50 \%$ \\
\hline Expection Value & 664 & 250 \\
\hline
\end{tabular}

$\mathrm{P}(\mathrm{A}, \mathrm{B})=\mathrm{P}(\mathrm{A}) * \mathrm{P}(\mathrm{B})=83 \% * 50 \%=41.5 \%$

And then We can calucate the covariance, which base on before date that we had got, There is a result as follow:

Covariance $=\mathrm{P}(\mathrm{A}, \mathrm{B}) *(\mathrm{~A}-\mathrm{E}(\mathrm{A})) *(\mathrm{~B}-\mathrm{E}(\mathrm{B}))=41.5 \% *(800-644) *(500-250) * 25=405$

The covariance is 405 , But We need to calucate random variable standards for gaining correlation and judge relationship between high-end function product and low-end function product. There is specific calucation process as follow:

The variance of high-end function product $6^{\wedge} 2=\mathrm{P}(\mathrm{A}) *(\mathrm{~A}-\mathrm{E}(\mathrm{A}))^{\wedge} 2 * 25=83 \% *(800$ $664)^{\wedge} 2 * 25=382792$

The variance of low-end function product $6^{\wedge} 2=\mathrm{P}(\mathrm{B}) *(\mathrm{~B}-\mathrm{E}(\mathrm{B}))^{\wedge} 2 * 25=50 \% *(500$ $250)^{\wedge} 2 * 25=781250$

After We can use 619 and 884 to calucate correlation and judge relationship between high-end function product and low-end function product as follow:

Correlation $=$ Covariance $/ 6(\mathrm{~A}) * 6(\mathrm{~B})=405 / 619 * 884=0.74$

Basing on the correlative value is between 1 and -1 , And the result is 0.74 , We can judge that are existence positive linear relation, When we are based on different customers demand to design high-end function product and low-end function product, We need to tend high-valued high-end function product in our product strategy.

\subsubsection{Findings \& Discussion}

Next we will examine the relationship between dependent variables and independent variables. For comparison purposes, to study and analyze the relationship between them, according to our previous hypothesis questions and research questions.

Basic characteristics of interviewees (Note: the longitudinal axis in the figure below is the number of people)

Of the 112 respondents, 45 were women and 67 were men. Among them, 28 are between 18 and 25 years old and 84 are between 26 and 35 years old.

\subsubsection{Occupation and education background distribution of respondents}

In our survey data, we can see from the figure that 7 people are free lance, 68 people are office workers and 37 people are students.

There were 41 people with master's degrees, 63 with bachelor's degrees and eight with high school degrees who took part in the survey.

The Sandard of High-end Function Product (A)

619
The Low-end Function Product (B) 
Figure 4. gender and age distribution

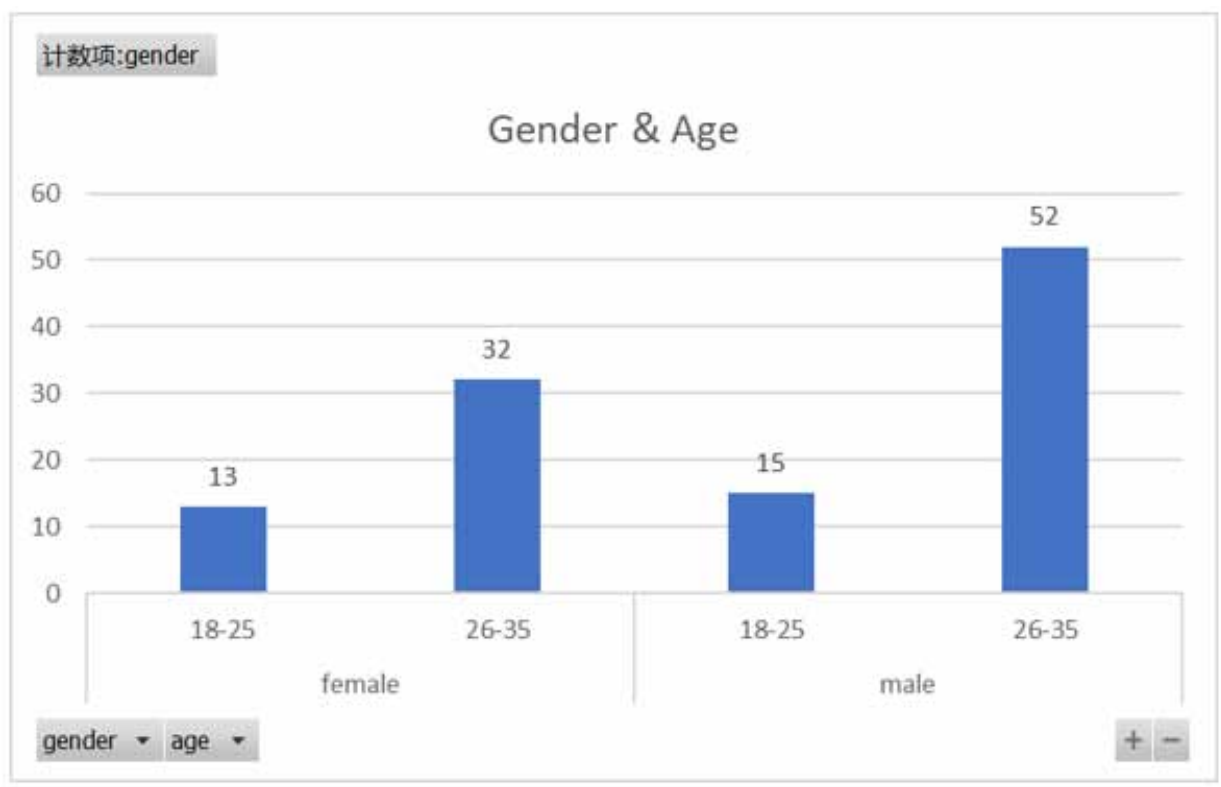

Figure 5. Occupation and Education background

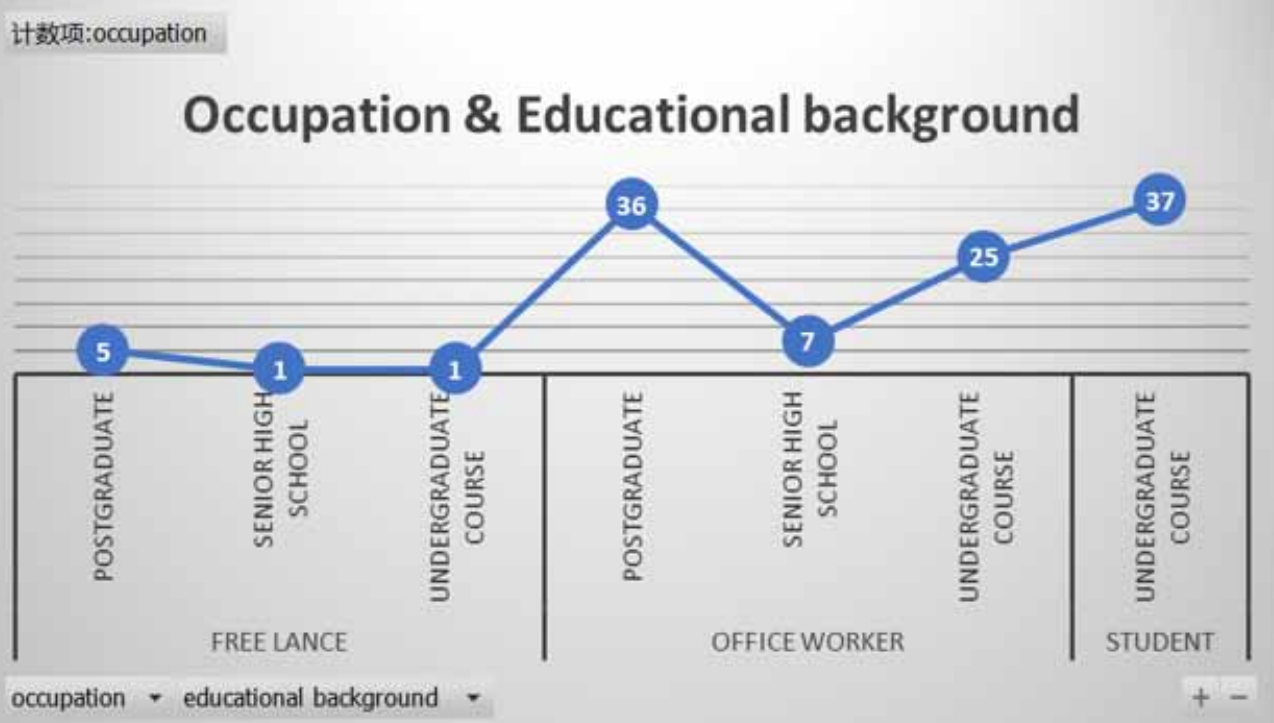




\section{Figure 6. Income}

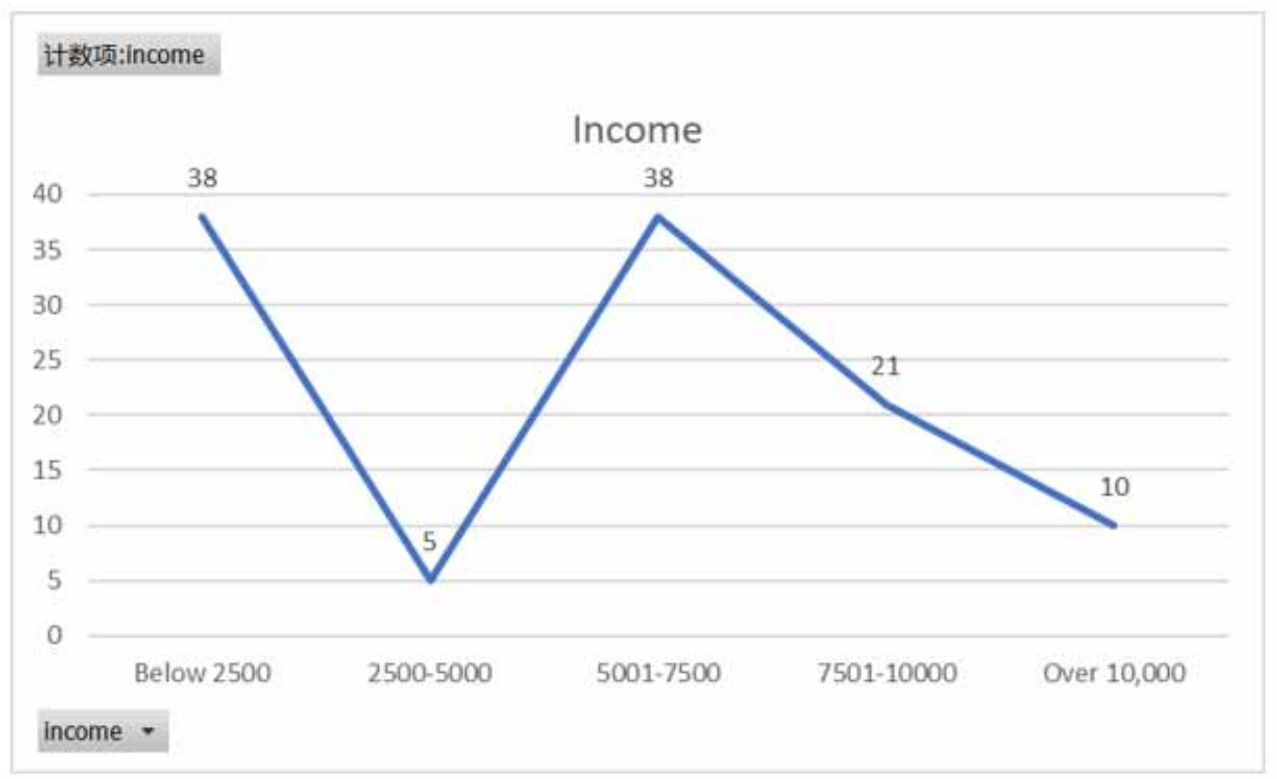

Figure 7. Have you ever learned about smart glasses

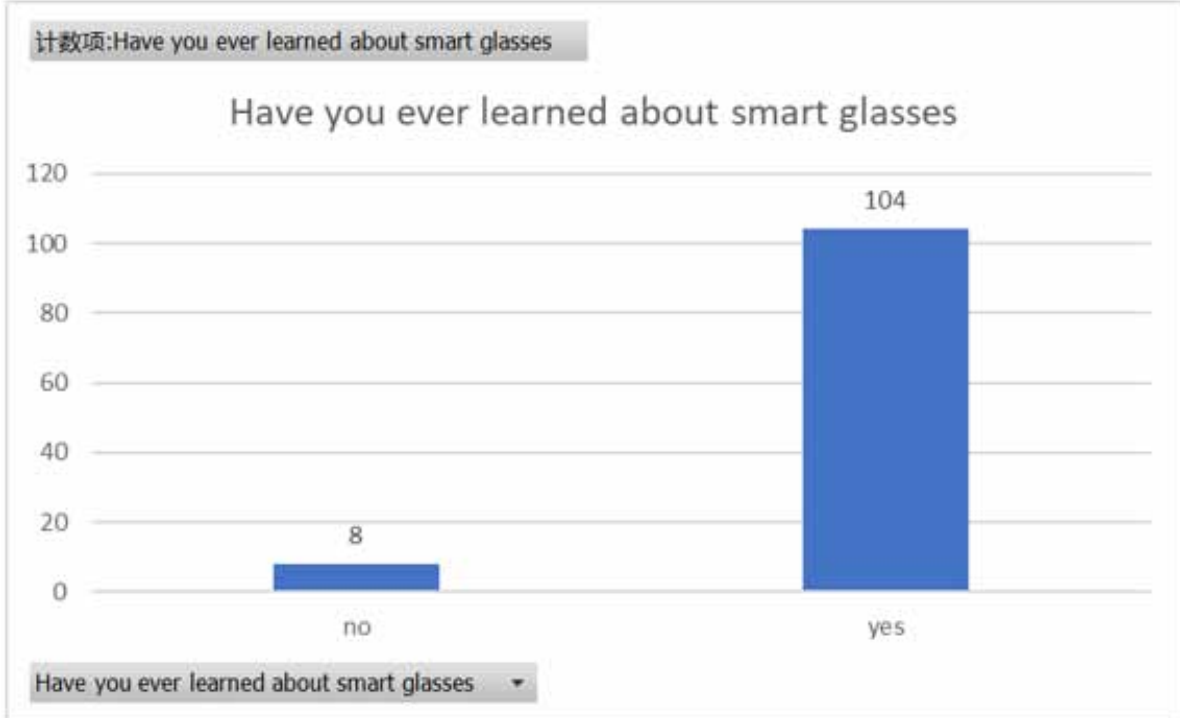




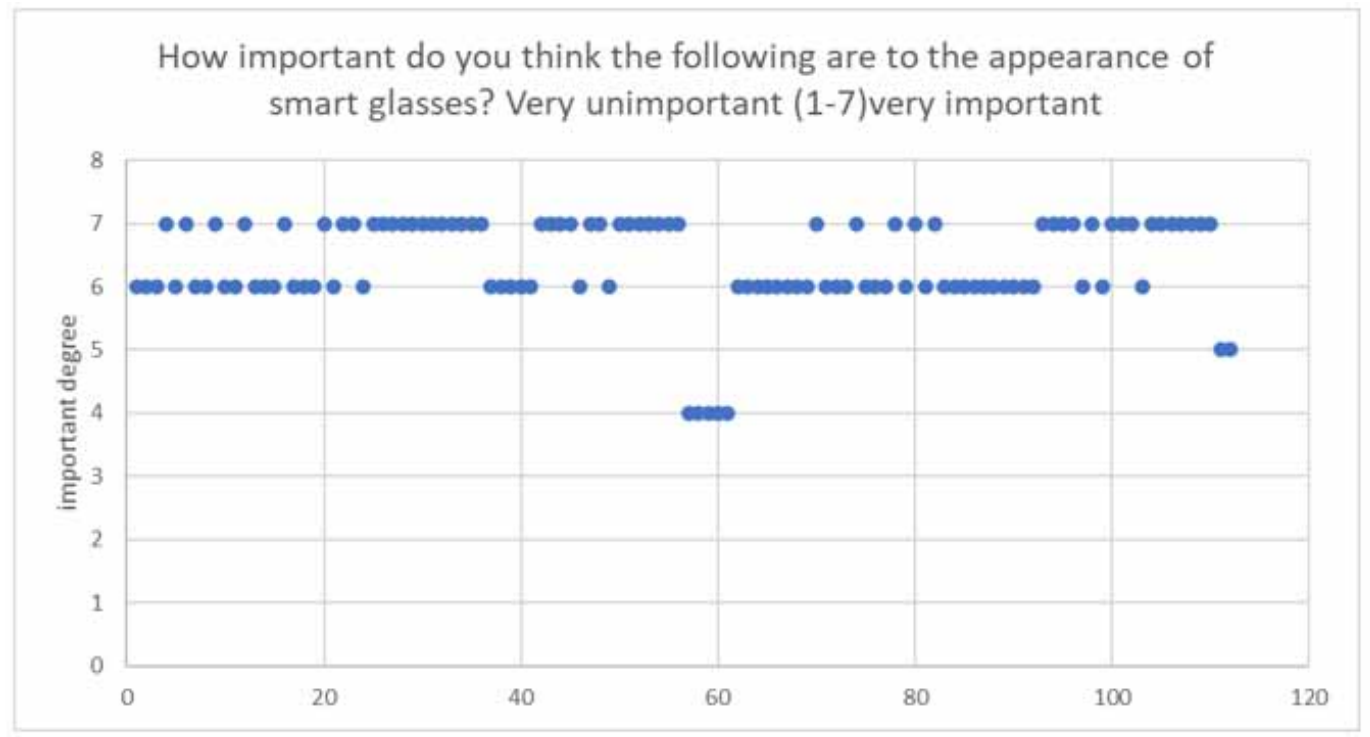

\subsubsection{Average Monthly Income of Respondents}

In the monthly average income data of interviewees, the number of people below 2500 and 50017500 is the same, both of which are 38. The number of people between 2500 and 5000 is at least 5 . The number of people in 7501-10000 and over 10000 is 21 and 10 respectively.

\subsection{Basic Status Quo of Customer Behavior}

The survey results showed that out of 112 respondents, 104 people, or $87 \%$ of the total, had known about smart glasses. Therefore, people's attention to smart glasses is very large.

\subsubsection{How important do you think the following are to the appearance of smart glasses?}

According to the figure analysis, while consumers are pursuing smart glasses, they also attach great importance to the appearance of smart glasses. Only 7 people chose the option below 6, with most agreeing that appearance is very important to smart glasses.

Even though the consumer market can still grow, we can already see use cases in various areas. For example, augmented reality guides can enhance a visitor's experience in a museum. The theater relies on eyeglasses to provide guests with instant subtitles, while visitors can easily find their way through anticipated directions and comments.

\subsubsection{How Important do you Think the Following are to the Price and Function of Smart Glasses?}

According to the survey data, the price of smart glasses is directly proportional to the degree of function of respondents. And most people agree that the price and functionality of smart glasses have a big impact on consumers.

\subsubsection{Do you think smart glasses are making people's life more convenient}

As can be seen from the chart, 104 interviewees think smart glasses can make people's life more convenient. Only 8 people gave NO. 
Figure 9. Price and Function

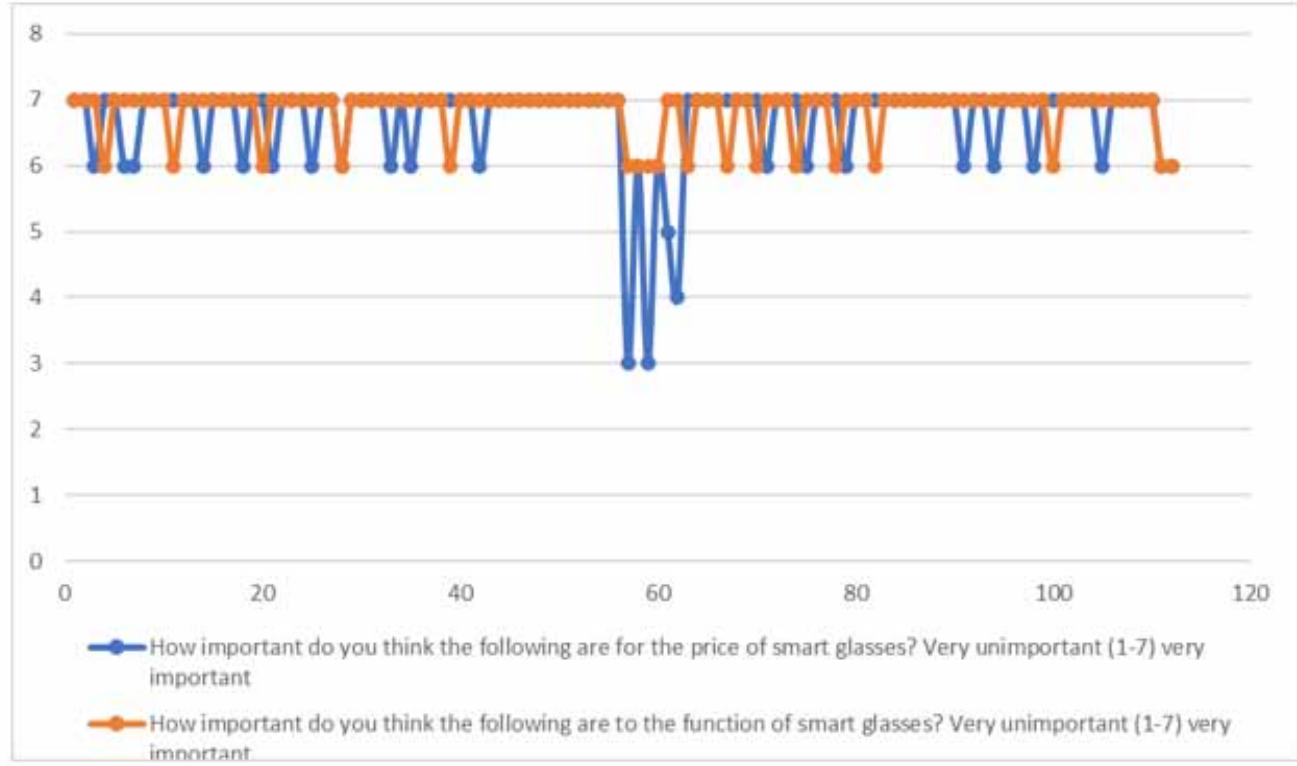

Figure 10. Do you think smart glasses are making people's life more convenient

计数项:Do you think smart glasses are making people's life more convenient

Do you think smart glasses are making people's life more convenient

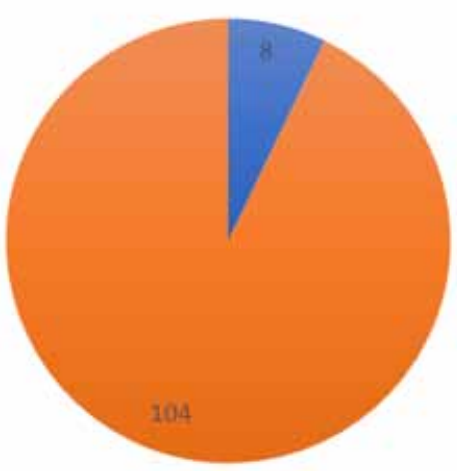

Do you think smart glasses are...

eno

wes 
Figure 11. What functions do you want smart glasses to have

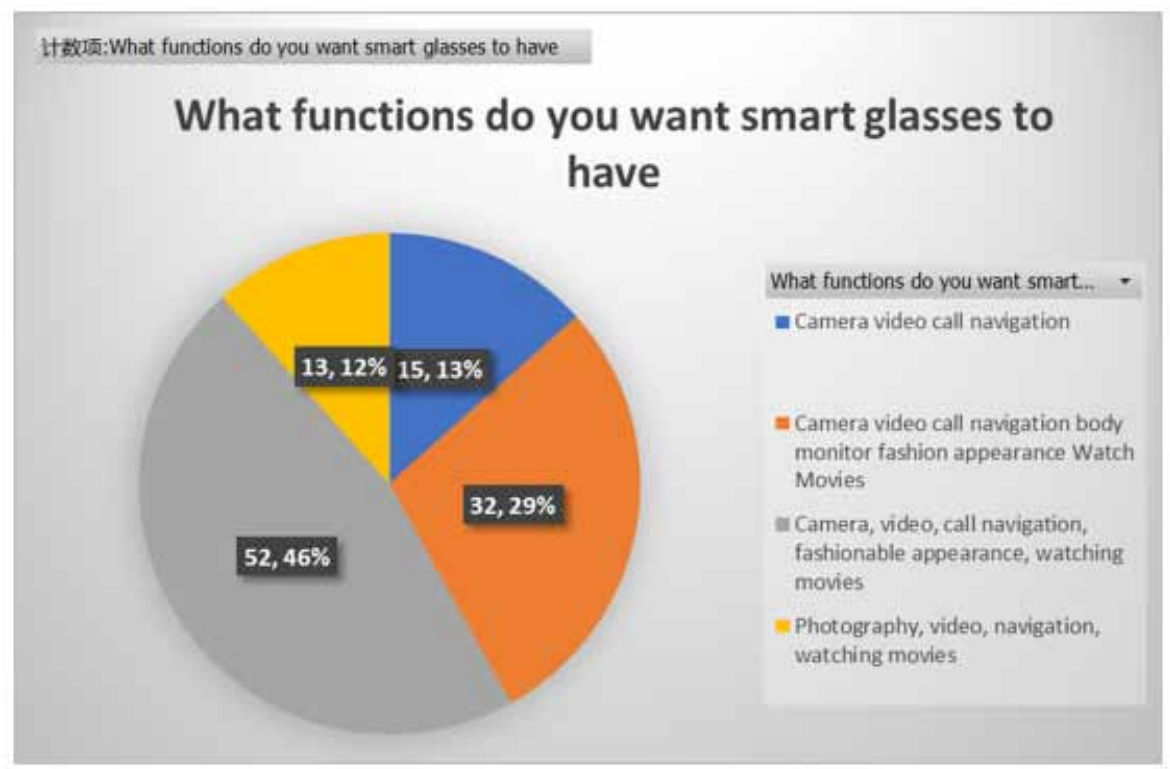

Figure 12. What price can you accept for smart glasses

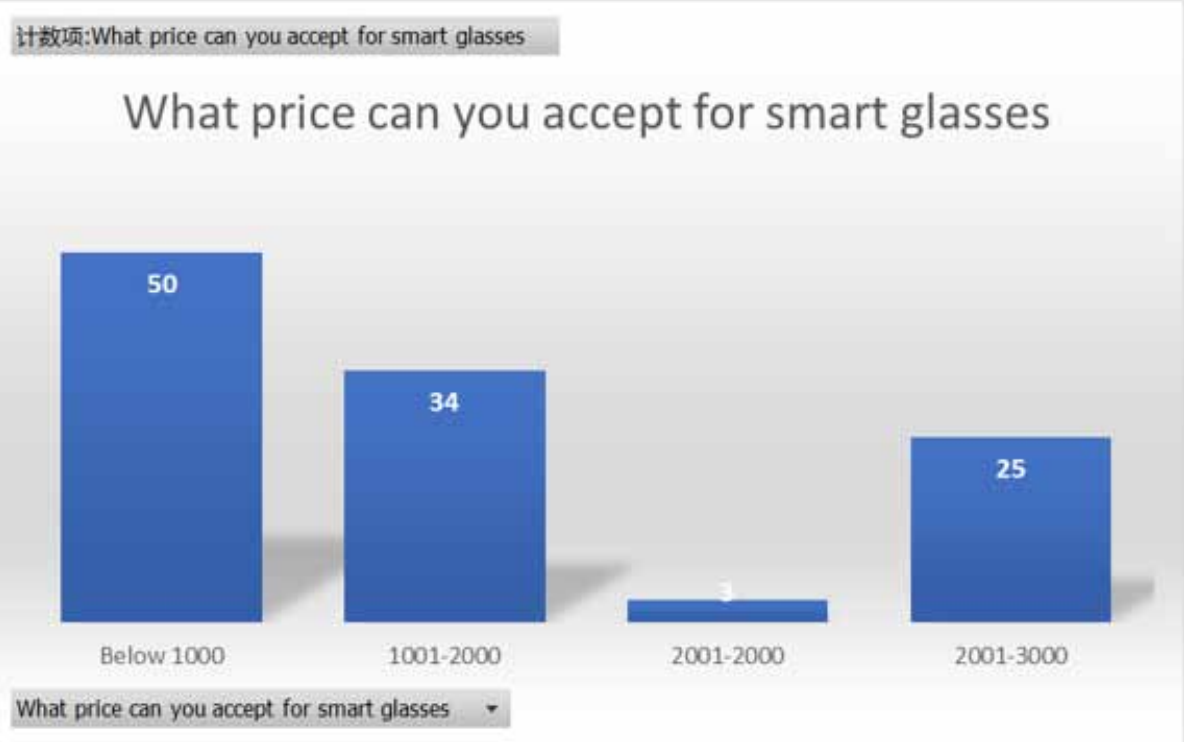


The current use of smart glasses is convincing more and more forward-thinking companies to get on board. Although still awaiting widespread public use, smart glasses have found valuable areas of operation, development and growth. So useful that it should come as no surprise to hear that tech giants like Apple, Facebook and Samsung are all working on their AR-powered smart glasses.

\subsubsection{What functions do you want smart glasses to have}

According to the figure, more than half of consumers want smart glasses to have functions such as taking photos, video, calling directions, good appearance and watching movies. This proportion accounts for $52.46 \%$. The lowest proportion is 13.12 percent. Consumers who choose smart glasses prefer to have useful video and navigation, etc.

\subsubsection{What price can you accept for smart glasses}

As can be seen from the figure, consumers generally accept the price of smart glasses less than 1000 . Fifty people chose less than 1,000. The number of people choosing 2000-3000 adds up to only 28 .

\section{THE SOLUTION ABOUT PRODUCT CANNIBALIZATION IN PRODUCT OR SERVICE ROLLOUT}

The intelligent glasses corporation that implement branding strategic key is precise market orientation, which is faced with the product performace that tend to cannibalization and consumpation deamand personalized real. Who can further exploit the branding uniqueness that base on the basis of high quality product. And Making customers gain material benefits and obtain a sence of satisfication and identity, Who will be a most big winer in branding competition.

Firstly, Determination strategy way. Development new intelligent glasses is the basic way of production corporation existence and development in furious market competitiveness and under the consumption demand which continually change. The corporation introduce new intelligent glasses whether success or not. Excpt for depending on the market demand, product quantity, advertisement dissemination and so on. The branding strangtic is a very important link. We will implement branding strangty of one brand for many products and use condition, strength and risk to analyze the strategy implemented feasibility.

Secondly, Solving the problem of product cannibalization. The situation of product cannibalization is to occupy corpoaration own market share. In this case it can also make corpoaration market increase. But The profit whether will be increased need to specifically analyze to new branding marginal income. So When introduce a new brand or product, We will use margin analysis way, which is based on the combination of new product, and analyze to the market influence of current and future for reasonably controlling product cannibalization situation as follow:

(1) We need to subdivide the intelligent glasses market for making its orientation more precise, feature more obvious.

(2) We need to grasp opportunity that the product will be launched, And then, A most important, We need to cultivate core competitiveness of ntelligent glasses, Because product cannibalization is competitive contest as well.

\subsection{Execpt For We Also Adopt Four Strategy For Solving Problem Of Product Cannibalization And Make Product Cannibalization Become Our One Of Competitiveness As Follow:}

(1) Market expansion strategy 
We can enhance the stability of corporation cash flow and income, reducing dependence of sign subdivided market by many brand strategy to expand whole market of corporation. If increasing market value is positively skewed in this way. We will permit the product cannibalization to occur. Because, If sale sustain stable either contribution of new product is more bigger than old product or there are new customers, who are attracted by new product, purchase the new product. Thus increasing total net income or net cash flow of corporation, It means that the product cannibalization is a correct strategy. We will make competitiveness and sale quantity as the target for bearing the loss of short profit which is caused by product cannibalization. Meanwhile, If new product can gradually replace old product and also maintain our market share, then the market expansion of product cannibalization will be a ideal market layout.

\section{(2) Defensing competitive strategy}

If a new product expect that will affect existence branding sales volume, then we will defer the new product to be introduce in market for defensing competitors when they introduce similar product or brand. It is effective The defensive strategy is for corporation in high competitive market. While the corporation need to comtinually. Meanwhile, We should seize opportunity that new product is launched for reducing influence of product cannibalization. Therefore, Our task is not so much to avoid situation of product cannibalization as controlling the situation when happen. So the defensing competitive strategy is an appropriate approach which adopt sale action for gaining profit effect.

\section{(3) Preemptive strategy}

The product cannibalization sometime is to effectively implement result of product combination management. Becouse The product cannibalization can make up for the product deficiency which may be supplied by compretitors or make a competitor's invasion ineffective. It means that we would like to make customers purchase our own products rather than select competitors.In this case, The Preemptive strategy will become a feasible selection for us. Althought, The strategy will competite with existing brand product in some aspect. But It can consolidate and expand our market, Meanwhile, It also attract customers of competitors, sustaining our own brand leading status, creating more market potential opportunities. It not only can offset that may lead to any sale quantity loss, But also It will forcibly occupy the market share of competitors. Therefore, This strategy is based on establishing a own defence to attack competitors. Thus It will be beneficial for increasing our own brand and market competitiveness.

\section{(4) Seizing the opportunity Of product cannibalization}

There are two aspect of strategy and decision when maeket go into opportunity. On the one hand is from strategic level, It is very important that select a product leader or follower for developing direction and distributing resource of corporation. If we would like to possess industrial leading position, We will seize opportunity of innovative product commercialization, So It will be most key that sustain the leading position to imitator. At that time. We will adopt the strategy of product cannibalization. On the other hand is from decision level. We need to measure when is most favorable opportunity that the new generational product is launched to market. It will depend on three important factor, Including competition, client and profit activity, If the product is prematurely launched to market, It may alienate customers and make competitors gain preferential opportunity.

Generally speaking, The product cannibalization is significant cost for introducing new products. And also is strong weapon for defending competition. Reasonably applying the product cannibalization strategy can increase corporation to whole marketable control for threatening competitor to occupy 
market. Meanwhile, The product cannibalization also exist nagetive effect. We can actively make it promote and enhance our own industrial competitiveness.

\section{BRANDING STRATEGIC ORIENTATION OF AR SMART GLASSES}

AR smart glasses that is core product of corporation belong to the high science product. How to make AR smart glasses satisfy the demand of customers and market? It need to determine by brand strategy.

\section{The Care Point Analysis of Branding Strategic Orientation of AR Smart Glasses}

If our product would like to be sustainably developed, we need to know the demand and psychology of customers, according to the demand market targeted to design and produce sale. Therefore It need technology means and strategic planning.

Nowadays, There are a lot of similar science products in electronic inductries and the competition is very furious. If the technology of AR smart glasses is our care of competitive advantage. We will discuss several important strategic thought and point as follow:

(1) We need to create more new product functions in AR smart glasses for making it possess more competition. rather than spend capital and energy in functions which is similar to competitiors.

(2) By now, The AR smart glasses had integrated into a lot of functions inside it, and The diversification of product function need technology to support, So our development purpose is toward light, thin and networked for integration direction in the future.

(3) We need to seize market trendency, Aiming at the consumer's consumption intention, advocating technical idea of low carbon environmental protection We think that the green energy is to determine core of electronic industries, So we need to quickly grab the market product type of AR smart glasses and will be included in network, service in design of AR smart glasses for increasing our product competitiveness.

\subsection{The Four Strategic Pattern Of AR Smart Glasses Branding Strategic Orientation}

\section{(1) Creating product brand}

The strategy of Creating product brand belong to one extreme in various branding strategy. It will respectively name for every sign product and do not appear our own corporation name basicly. The strategy also endow exclusive value, personality, identifying features and positioning for every brand and make them all become new brands when are launched market by corporation. And Each brand can target a specific customers group. It also make each branding performance and value of corporation more easy evaluated, and distribute decision more reasonable. But there is a potential risk in creating product branding strategic orientation of AR smart glasses, which so-called product orirntation inaccurate, If customer cannot distinguish between product brands, Then There will be a internecine condition between products of corporation.

\section{(2) Creating a series of product brands}

This way will make products exist under the same brand name. And there are same basic identify feature. But the effect are different. The series of products can defend that the classification of products are drastically hit. Therefore, When the corporation expand them own brand for satisfied other clients and subdivide marker, Individual products brand will become a series of brands.

(3) Creating product category brands 
So-called product category brands, It means that will put a group of product or service into a brand. And Using a basic identify to launch. It is different with product series brands. Although There are similar to the basic functions, But they are different performance level.

(4) Creating corporation brand

We will create our own corporation brand as market strategy of AR smart glasses, Specific contents include: Firstly, The corporation name will used as primary brand name and conduct dissemination, In this case, Our corporation supply products or services which do not use single brand. And brand of corporation will be focused than product brand for making corporation to identify feature and image. Secondly, We will use a noticeable branding name, and guarantee its quantify and creditable reliability.In this way The branding guarantee will advance product sales, The strategy is called supporting brand. In addition, We also focus on branding strategic orientation of AR smart glasses for increasing the value of brand competitiveness as follow:

(1) Our brand possess the function of identifing goods, It provide baiss for disseminating advtisement, sales promotion and so on.

(2) The right to exclusive use of trademarks is protected by law, It will forcibly contain illegal competitors to occupy our own product market.

(3) There is a trademark of good goodwill, It will be beneficial to the AR smart glasses to enter matket.

(4) The AR smart glasses will have more stronger attraction to customers being beneficial to increase our market share.

The brand are valuation coefficient and identification mark of intrinsic quality and maeket value, and It also is intingible that corporations competes in market. If corporations would like to win in competition, They need to protect them own brand and goodwill, So the product quality is very important, With the products quality are continually increased, The brand of corporations will establish a more excellent corporate image in process.

Proving the quality and source in sale process are contribute to the customers to select brand which they like, and they will also gain a more high sence of satisty. If the quality of product have some problems, The customers also will gain compensation and value-added service of loss.

\section{STRATEGIC ORIENTATION AND METHOD OF THE AR SMART GLASSES}

\subsection{We Will Firstly Think About Several Key Questions.}

Q1: What do the strategic orientation help corporation?

Q2:The AR smart glasses is a emerging intelligent equipment in recent years. If corporation can seize the category brand of AR smart glasses, They will process industries dominant right in the future of science development How to become a excellent category brand in industries the AR smart glasses?

\subsection{We Need To Think About The Unique Of Target Customers Group Whether Can Be Satisfied With The Demand Of Customers Group}

Basing on the acquisition group of AR smart glasses are the young man and the aged. So the strategic orientation need to focus on the feature and demand of target customers as core, and scheme a way of strategic orientation which is suitable for the commercial development of the AR smart glasses. 
Table 2. 4PS marketing theory

\begin{tabular}{|l|l|l|l|}
\hline \multicolumn{2}{|c|}{ 4PS-product strategy } & \multicolumn{2}{c|}{ 4CS-customer strategy } \\
\hline Product & $\begin{array}{l}\text { Determining service scope, } \\
\text { peoduct orientation and brand }\end{array}$ & Customer & $\begin{array}{l}\text { researching customers demand and } \\
\text { supplying relevant product and } \\
\text { service }\end{array}$ \\
\hline Price & $\begin{array}{l}\text { Determining basis price, payment } \\
\text { method and discount }\end{array}$ & Cost & $\begin{array}{l}\text { Thinking about the payment cost of } \\
\text { customer and cost of goods sale. }\end{array}$ \\
\hline Place & indireact place and direct place & Convenience & $\begin{array}{l}\text { Thinking about the convenience of } \\
\text { third physical distribution }\end{array}$ \\
\hline Promotion & $\begin{array}{l}\text { advertisement, staff sale, business } \\
\text { promotion and public relationship. }\end{array}$ & Communication & $\begin{array}{l}\text { ommunicating with customers } \\
\text { actively and gaining their } \\
\text { satisfaction level and trust }\end{array}$ \\
\hline
\end{tabular}

\subsection{Analyzing Feature And Function Of Product Itself}

It is branding important meaning that the brand can make people think of product certain property. The AR smart glasses are wearable intelligent equipment. The people can reaval virtual things and real- timely record date in daily life, Meanwhile it also synchronize with information and material of smart phone, People can conduct online shopping, remote study, virtual reality operation and so on.

\subsection{Confirming Brand Core Value}

The strategic orientation is to seize customers demand as core. Therefore, Making strategic orientation before, We must know our own brand advantage when face with the demand of different customers. And then, We will use advantage that include price, service and innoative technology to increase brand competitiveness on ensuring basis of products quality.

\subsection{Distinguishing From Orientation Of Competitors}

The strategic orientation should be different with other competitors on brand personality and image style. So, It is to make key of brand differentiation that we firstly need to know the method of competitors who created them own brand, At the beginning We will generally analyze the strategic orientation of current and past. A effective way is to collect representative advertisements of competitors and estimate them dissemination expense. And then classify to these advertisements. In this way it will make our brand orientation become more precise.

\subsection{Strategic Orientation Meaning Of The AR Smart Glasses}

The orientation devote to establish a specific and valuable location in customers mind. And It also become a representable brand in certain type or feature products, Thus, It rapidly affect acquisition selection of customers. When customers have relevant demand, They can think of our brand and select it. And Our brand orientation will replace unqire value of product in customers mind, It have irreplaceable acquisition value.

\subsection{Using 4PS and 4CS Marketing Theory Estimate Product Strategy}

Firstly, We will analyize the product, price, promotion, place and Stratrgy of other competitors. It is so-called 4PS marketing theory.

According to the 4PS marketing theory, We will analyze maketing strategy from the perspective of management decisions. The foctor that has influence on marketing activity can be divided into two categories. The One is that corporation cannot control foctor, which cannot control market, including marking environment, micro environment and macro environment. The other is that corporation can control foctor, which include products, brand, advertisement, place, price, mark and so on. So The 
Table 3. Price comparison of different brand products

\begin{tabular}{|c|c|c|c|}
\hline Competitor & Google smart glasses & Microsoft smart glasses & Apple smart glasses \\
\hline high-end & 1500 & 1500 & 1800 \\
\hline middle-end & 1200 & 1000 & 1500 \\
\hline low-end & 800 & 900 & 1200 \\
\hline Place & $\begin{array}{c}\text { delivery, business } \\
\text { cooperation, physical store }\end{array}$ & delivery, physical store, dealer & $\begin{array}{c}\text { business cooperation, } \\
\text { physical store, dealer }\end{array}$ \\
\hline Promote & $\begin{array}{c}\text { advertisement, sales } \\
\text { promotion }\end{array}$ & advertisement, sales promotion & advertisement \\
\hline
\end{tabular}

4PS adapt to us to analyze the market of AR smart glasses and according to the 4PS to formulate strategy respectively as follow:

(1) Product strategy: We will be based on the demand of customers to design the function of AR smart glasses, For example: According to the different industries, like hospital, business, collage, divide and compose our product, which include type, size, quality, functions, feature, various services measure and so on.

(2) Pricing strategy: We will be based on the market rule to make and change price for realizing our marketing purpose. The price contain basic price, discount price, rebate, payment term, business credit, and use a variety of pricing combination to face with market change. Meanwhile, We also refer to the price of competitors to adjust our pricing strategy.

(3) Placing strategy:We will reasonably select distribution channels and circulation channels, organization goods physical store, to realize our marketing goal. Meanwhile, We will focus on the combination and application of some key controllable foctors, which contain transport. dealer, commodity circulation link, delivery, alliance business, channel coverage, physical store, website set and storage.

(4) Promoting strategy: We will use a variety of transmission means to stimulate consumption and the buying inclination of custumers, and promote products sale way to realize marketing purpose, We will use different ways, which include advertisement, which is related to the promotion, staff sale, sales promotion, public relationship and some foctors combination are controlled.

Table 4. Application of pricing to products

\begin{tabular}{|c|c|c|c|}
\hline Type & high-end & middle-end & low-end \\
\hline Inductry & Hospital,Manufacture inductries & Business,Collage & Customer \\
\hline Function & $\begin{array}{c}\text { Vritual reality, Similative } \\
\text { operation, Imitative practice, } \\
\text { Database }\end{array}$ & $\begin{array}{c}\text { Vritual reality, Remote } \\
\text { study,Database } \\
\text { Interation }\end{array}$ & $\begin{array}{c}\text { Shopping Comunication } \\
\text { Price }\end{array}$ \\
\hline Place & $\begin{array}{c}\text { - delivery, alliance business, } \\
\text { business cooperation }\end{array}$ & 1000 & website,physical store \\
\hline Promote & advertisement, staff sale & public relationship & sales promotion \\
\hline
\end{tabular}


We had collected three product market information of typical companies, Google, Microsoft, Apple, and analyize the price, palce and promote of them different product, Thus, Preparing for implementing and selecting our product strategies.

According to the information above, We are based on the product information and market situation of competitors to customize the price and services of different products. And We will continually improve the content of product to make it more suitable customer demand and possess industry advantages in the future.

\subsection{Meanwhile,We also apply $3 R$ model to assist $4 \mathrm{Ps}$ for making it more perfect. Specific content include customers retention, related sales, customers referral. I will introduce $3 R$ model in detail in the following.}

(1) Customers retention: We need to actively establish a long-term relationship with customers and sustain a continuous communication for retaining current customers, Because If the customers retained rate increase, The profit of corporation will continually enhance and sustain a stable position. Meanwhile, We gain the resource cost of customers that are more higher than retaining a regular customer, and We will create extra profit from regular customers. Therefore, We should focus on regular customers for decreasing the resource cost of new customers.

(2) Related sales: Due to the regular customers had establish confidence for our corporation product, So our cost of advertisement and sale will be decreased. Meanwhile, The regular customers will constantly buy our new product or products upgraded. Therefore, Our profit margin will keep a rising postion.

(3) Customers referral: If regular customers tend to our products by comparing with other products, They will like our products better and recommend these products to their relatives and friends, In this case The confidence level and effect of customers dissemination is more higher than corporation own advertisement.And The corporation will also possess more loyal customers, creating more profit in the future.

\subsection{We Will Analyze Behavior and Feature of Customers by 4SC Theory, Which Include Customer, Cost, Convenience, Communication.}

(1) Customer strategy: We need to know and rearch the demand of our target customers, And We should pay attention to the customer value rather than just products and services.

(2) Cost strategy: Except for the producing cost, The acquisition of customers are very important for the corporation, Because, It means that the products are priced ideal situation, lower than customer's psychological price, In addition, The cost not only contain cash expense, but also indule wasting time, physical and mental expenditure, as well as buying risks.

(3) Convenience strategy: When we use the distribution strategy by 4PS, We also think about the customer's convenience rather than ourself. We should make customers who enjoy convenience by pre-sale, sale and after-sales service. Because, the convenience is important constituent part of customer value for corporation.

(4) Communication strategy: The communication strategy can replace promotion in 4P, We think that the effective communication can establish a good relationship that based on common benefit with customers, It is efficient way that dominate customers to sell our product by two sides communication to realize each other purpose.

\section{CONCLUSION}

Through 112 online random surveys, the study found out the thoughts of potential customers of smart glasses. Technological developments in smart glasses make the future possible. But it has not 
become an ordinary household item like smartphones and tablets. Through this investigation and research, it is found that one of the factors that affect potential consumers is price cost, and the impact of functions on consumers' purchases. However, with the decline in prices and the enhancement of functions, smart glasses will be adopted by more people in the future. Therefore, the development and exploration of software and hardware around smart glasses and the innovation of appearance have become the trend of consumer electronics. Bring more innovative ideas to the future. 


\section{REFERENCES}

Atallah, Z. A. (2021), JomMedicMinder: Live or Dead. IEEE Symposium on Computer Applications \& Industrial Electronics, 100-105.

Baek, J., \& Choi, Y. (2020). Smart Glasses-Based Personnel Proximity Warning System for Improving Pedestrian Safety in Construction and Mining Sites. International Journal of Environmental Research and Public Health, 17,1422 .

Basoglu, N., Ok, A. E., \& Daim, T. U. (2017). What will it take to adopt smart glasses: A consumer choice based. Technology in Society, 50, 50-56.

Bertarini. (2014). Smart Glasses: Interaction. Privacy and Social Implications Ubiquitous Computing Seminar FS2014 Student Report.

Bower, M., \& Sturman, D. (2015, October). What are the educational affordances of wearable technologies? Computers \& Education, 88, 343-353.

Brohm, D., Domurath, N., Glanz-Chanos, V., \& Grunert, K. G. (2017). Future trends of augmented reality. Augmented Reality for Food Marketers and Consumers, 1681-1685.

Chau, P. Y. K., \& Hu, J. H. (2002). Investigating healthcare professionals' decisions to accept telemedicine technology: An empirical test of competing theories. Information \& Management, 39, 277-287.

Chen, K., \& Chan, A. H. S. (2014, February). Predictors of gerontechnology acceptance by older Hong Kong Chinese. Technovation, 34(2), 126-135.

Chin, J., \& Lin, S. (2015). Investigating users' perspectives in building energy manage- ment system with an extension of technology acceptance model: A case study in indonesian manufacturing companies. Procedia Computer Science, 72, 31-39.

Chung, S., Lee, K. Y., \& Kim, K. (2014, September). Job performance through mobile enterprise sys- tems: The role of organizational agility, location independence, and task characteristics. Information \& Management, 51(6), 605-617.

Daim, T., Basoglu, N., Kargin, B., \& Phan, K. (2014). Service innovation adoption: Case of value added mobile services. Journal of the Knowledge Economy, 5(4), 784-802.

Daim, T., Basoglu, N., \& Tanoglu, I. (2010). A critical assessment of information technol- ogy adoption: Technical, organizational and personal perspectives. International Journal of Business Information Systems, 6(3), 315-335.

Daim, T., Basoglu, N., \& Topacan, U. (2013). Adoption of health information technologies: Case of wireless monitor for diabetes and obesity patients. Technology Analysis and Strategic Management, 25(8), 923-938.

Davis, F. D. (1989). Perceivedusefulness,perceivedeaseofuse,anduseracceptanceof information technologies. Management Information Systems Quarterly, 13, 319-340.

Dehghani, M., Kim, K. J., \& Dangelico, R. M. (2018). Will smartwatches last? Factors contributing to intention to keep using smart wearable technology. Telematics and Informatics, 35(2), 480-490.

Ducey, A. J., \& Coovert, M. D. (2016, September). Predicting tablet computer use: An extended Tech- nology Acceptance Model for physicians. Health Policy and Technology, 5(3), 268-284.

Dutot, V. (2015). Factors influencing Near Field Communication (NFC) adoption: An extended TAM approach. The Journal of High Technology Management Research, 26(1), 45-57.

Ng, Kang, Mahmood, Choo, Wong, Phan, \& Lim. (2016). Exostructure Services for Infrastructure Resources Optimization. Journal of Telecommunication, Electronic \& Computer Engineering, 8(4), 65-69.

Fischer, G. (2001). User modeling in humanecomputer interaction. User Modeling and User-Adapted Interaction, $11,65-86$.

Gong, X. X. (2021). Smart glasses implementation in hospital. International Journal of Business Strategy and Automation, 2(4), 1-9. 
Griggs, J. (2015, March 21). Wearable technology could revolutionise how we monitor health. New Scientist, 225(3013), 24-25.

Hafsa, S., \& Majid, M. A. (2020, October). Learnability Factors for Investigating the Effectiveness of Augmented Reality Smart Glasses in Smart Campus. IOP Conference Series. Materials Science and Engineering, 958(1), 012005 .

Han, D. I. D., Tom Dieck, M. C., \& Jung, T. (2019). Augmented Reality Smart Glasses (ARSG) visitor adoption in cultural tourism. Leisure Studies, 38(5), 618-633.

Hao, Y., \& Helo, P. (2017, June). The role of wearable devices in meeting the needs of cloud manufacturing: A case study. Robotics and Computer-integrated Manufacturing, 45, 168-179.

Hartson, H. R. (1998). Human-computer interaction: Interdisciplinary roots and trends. Journal of Systems and Software, 43, 103-118.

Haucke, F. (n.d.). Smartphone-enabled social change: Evidence from the Fairphone case? Age, 20(19), 4-7.

Hein, D. W., Jodoin, J. L., Rauschnabel, P. A., \& Ivens, B. S. (2017). Are wearables good or bad for society?: An exploration of societal benefits, risks, and consequences of augmented reality smart glasses. In Mobile technologies and augmented reality in open education (pp. 1-25). IGI Global.

Hermelbracht, A., \& Koeper, B. (2006). Development of new library services by means of Conjoint Analysis. Library Hi Tech, 24, 595-603.

Ingham, J., Cadieux, J., \& Berrada, A. M. (2015, January). e-Shopping acceptance: A qualitative and metaanalytic review. Information \& Management, 52(1), 44-60.

Kargin, B., Basoglu, N., \& Daim, T. (2009). Factors affecting the adoption of mobile ser- vices. International Journal of Services Sciences, 1(2), 29-52.

Ku, P. S., Peng, Y. H., Lin, Y. C., \& Chen, M. Y. (n.d.). PeriText: Utilizing Peripheral Vision for Reading Text on Augmented Reality Smart Glasses. Academic Press.

Kummer, T., Recker, J., \& Bick, M. (2017, January). Technology-induced anxiety: Manifestations, cultural influences, and its effect on the adoption of sensor-based technology in German and Australian hospitals. Information \& Management, 54(1), 73-89.

Lamkin, P., \& Charara, S. (2017). The best smartglasses 2017: snap, Vuzix, ODG, Sony \& more. Wearable. Available at: https://www.wareable.com/headgear/the-best-smartglasses-google-glass-and-the-rest

Larson, B. J., Mejia, D., Marquez, T., \& Reinhard, P. (2016, June). Using wearable technology to optimize maternal positioning and facilitate progression of labor. Journal of Obstetric, Gynecologic, and Neonatal Nursing, 45(3), S23.

Lazard, A., \& Mackert, M. (2014, October). User evaluations of design complexity: The impact of visual perceptions for effective online health communication. International Journal of Medical Informatics, 83(10), $726-735$.

Lazuras, L., \& Dokou, A. (2016, February). Mental health professionals' acceptance of online counseling. Technology in Society, 44, 10-14.

Matsuhashi, K., Kanamoto, T., \& Kurokawa, A. (2020). Thermal Model and Countermeasures for Future Smart Glasses. Sensors (Basel), 20(5).

Ng, Choo, Wong, Phan, \& Lim. (2012). Malaysia SME ICT During Economic Turbulence. International Conference on Information \& Computer Network, 67-71.

$\mathrm{Ng}$, Kang, Choo, Wong, Phan, \& Lim. (2015). Beyond cloud infrastructure services in medium-size manufacturing. International symposium on mathematical sciences \& computing research, IEEE Explore, 150-155.

Ng. (2018). EaaS Optimization: Available yet hidden information technology infrastructure inside medium-size enterprises. Journal of Technological Forecasting and Social Change, 132(July), 165-173.

Ng. (2019). EaaS Infrastructure Disruptor for MSE. International Journal of Business Information Systems, 30(3), 373-385. 
$\mathrm{Ng}$, Loh, \& Eaw. (2020). Grid Computing for MSE during Volatile Economy. International Conference on Control, Automation and Systems, IEEE Explore, 709-714.

Ng \& Eaw. (2021a). Making financial sense from EaaS for MSE during economic uncertainty. Advances in Intelligent Systems and Computing, 1(1), 976-989.

Ng \& Eaw. (2021b). Still Technology Acceptance Model? Reborn: Exostructure as a Service Model. International Journal of Business Information Systems.

Ng, , Yin, , Wan, , \& Nazmudeen, . (2011). Energizing ICT Infrastructure for Malaysia SME during Economic Turbulence. Student Conference on Research and Development, IEEE Explore, 328-322.

Ng, J. P. S., Mahmood, A. K., Choo, P. Y., Wong, S. W., Phan, K. Y., \& Lim, E. H. (2014). IaaS Cloud Optimization during Economic Turbulence for Malaysia Small and Medium Enterprise. International Journal of Business Information Systems, 16(2), 196-208.

Ng, J. P. S., Mahmood, A. K., Choo, P. Y., Wong, S. W., Phan, K. Y., \& Lim, E. H. (2015). Barebone cloud IaaS: Revitalization disruptive technology. International Journal of Business Information Systems, 18(1), 107-126.

Ng \& Kang. (2016). Beyond barebone cloud infrastructure services: Stumbling competitiveness during economic turbulence. Journal of Science and Technology, 24(1), 101-121.

Ng, Soon, Moy, Mahmood, Wan, Yuen, Hui, \& Theam. (2016). EaaS: Available yet Hidden Infrastructure inside MSE. 5th International Conference on Network, Communication, and Computing, ACM International Conference Proceeding Series, 17-20.

Rauschnabel, P. A., Brem, A., \& Ivens, B. S. (2015). Who will buy smart glasses? Empirical results of two premarket-entry studies on the role of personality in individual awareness and intended adoption of Google Glass wearables. Computers in Human Behavior, 49, 635-647. doi:10.1016/j.chb.2015.03.003

Rauschnabel, P. A., Brem, A., \& Ro, Y. (2015). Augmented reality smart glasses: definition, conceptual insights, and managerial importance. Unpublished Working Paper, The University of Michigan-Dearborn, College of Business.

Rzayev, R., Wozniak, P. W., Dingler, T., \& Henze, N. (2018). Reading on Smart Glasses: The Effect of Text Position. Presentation Type and Walking.

Sharma, N., \& Bathla, R. (2019, November). Coalescing Artificial Intelligence with Augmented Reality to vitalize Smart-Glasses. In 2019 4th International Conference on Information Systems and Computer Networks (ISCON) (pp. 149-154). IEEE.

Suh, S. E., \& Roh, J. S. (2015). A study on smart fashion product development trends. The Research Journal of the Costume Culture, 23(6), 1097-1115.

Tan, Y. Y. (2020). JomLinerapy: Therapist on your plam. IEEE International Women in Engineering Conference on Electrical and Computer Engineering, 33-38.

Vica, V. (2019). JomImage SnapFudo: Control your food in a snap. IEEE International Conference on Engineering Technologies and Applied Sciences, 1-5

Vivilyana, V. (2020). JomImage: Weight control with mobile SnapFudo. Advances in Intelligent Systems and Computing, Springer, 1252(3), 168-180. 